УДК $377 ; 378 ; 316.3$

ББК $60.56 ; 74.4$

DOI $10.31554 / 2222-9175-2019-35-195-199$

Ю. Г. Бюраева

РОАЬ ОБРАЗОВАНИЯ В ВОСПРОИЗВОАСТВЕ СОЦИААЬНО-ПРОФЕССИОНААЬНОЙ СТРУКТУРЫ РЕСПУБАИКИ БУРЯТИЯ

Рассматривается механизм воспроизводства социально-профессиональной структуры в Республике Бурятия. Анализ проведен на основе методологии Ф. Э. Шереги. Показано усиление диспропорций профессиональной структуры населения, что обесценивает высшее образование и порождает социальную напряженность и рост безработицы в молодежной среде. Выявлена необходимость изменения структуры профессиональной подготовки, выравнивания разрыва в межотраслевой и межпрофессиональной оплате труда и развития системы дополнительного профессионального образования как институционального регулятора рынка труда и воспроизводимой социально-профессиональной структуры общества.

Ключевые слова: подготовка кадров, социально-профессиональная структура, профессиональное образование, Республика Бурятия.

Yu. G. Byuraeva

\title{
ROLE OF EDUCATION IN REPRODUCTION OF SOCIAL AND PROFESSIONAL STRUCTURE IN THE REPUBLIC OF BURYATIA
}

The article examines the mechanism of reproduction of social and professional structure in the Republic of Buryatia. The analysis has been conducted by the methods of F. E. Sheregi. It has shown the increasing imbalances in professional structure of population, that depreciate higher education and cause social tension and growth of unemployment among the young people. There is identified the need to change the structure of vocational training, levelling the gap in interbranch and interprofessional wages and the development of the system of additional professional education as institutional regulator of job market and social and professional structure of society.

Keywords: training of specialists, social and professional structure, professional education, the Republic of Buryatia.

бразование как социальный институт выступает в качестве механизма вос-
производства социально-профессиональной структуры общества. В современном иерархическом обществе определенную статусную позицию можно занять в первую очередь благодаря наличию профессионального образования, при условии, что эта позиция никем не будет занята. Наследование статуса по мотивам родственных отношений не может иметь массового характера и на социально-классовую структуру особого влияния не оказывает.

В этой связи цель данной статьи - показать, каким образом профессиональное образование (ПО) обеспечивает воспроизводство социальной структуры общества

БЮРАЕВА Юлия Григорьевна - доктор социологических наук, ведущий научный сотрудник отдела региональных экономических исследований Федерального государственного бюджетного учреждения науки «Бурятский научный центр СО РАН» (Улан-Удэ, Россия). E-mail: yulbur@yandex.ru. 
в Республике Бурятия на основе методологии, предложенной Ф. Э. Шереги [2010, 2015], который рассматривает современную социально-профессиональную (классовую) структуру российского общества, опираясь на официальные статистические данные. Применим указанный принцип к региональной ситуации (табл. 1).

Таблица 1

Социально-профессиональная структура общества РБ, 2017 г.

\begin{tabular}{|l|c|l|}
\hline \multicolumn{1}{|c|}{ Статус } & $\begin{array}{c}\text { Доля } \\
\text { от занятого } \\
\text { населения, } \%\end{array}$ & $\begin{array}{l}\text { Требуемый мин. } \\
\text { уровень ПО }\end{array}$ \\
\hline Руководители & 5,8 & ВО \\
\hline Специалисты высшего уровня квалификации & 22,0 & ВО \\
\hline Специалисты среднего уровня квалификации & 11,4 & $\begin{array}{l}\text { СПО (спец-ты ср. } \\
\text { звена) }\end{array}$ \\
\hline $\begin{array}{l}\text { Квалифицированные рабочие сельского и лесного хо- } \\
\text { зяйства, рыбоводства и рыболовства }\end{array}$ & 2,8 & $\begin{array}{l}\text { СПО (спец-ты ср. } \\
\text { звена) }\end{array}$ \\
\hline $\begin{array}{l}\text { Квалифицированные рабочие промышленности, строи- } \\
\text { тельства, транспорта и рабочие родственных занятий }\end{array}$ & 12,3 & $\begin{array}{l}\text { СПО (спец-ты ср. } \\
\text { звена) }\end{array}$ \\
\hline $\begin{array}{l}\text { Служащие, занятые подготовкой и оформлением доку- } \\
\text { ментации, учетом и обслуживанием }\end{array}$ & 3,1 & СПО (кв. рабочие) \\
\hline $\begin{array}{l}\text { Работники сферы обслуживания и торговли, охраны } \\
\text { граждан и собственности }\end{array}$ & 16,0 & СПО (кв. рабочие) \\
\hline $\begin{array}{l}\text { Операторы производственных установок и машин, } \\
\text { сборщики и водители }\end{array}$ & 15,5 & СПО (кв. рабочие) \\
\hline Неквалифицированные рабочие & 11,1 & $\begin{array}{l}\text { СПО (кв. рабочие) } \\
\text { или без ПО }\end{array}$ \\
\hline
\end{tabular}

* Рассчитано по: [Статистический ежегодник 2018: 86].

Из указанных данных следует, что для воспроизводства занятых на двух первых позициях (скорее только второй, поскольку руководителями после окончания вуза не становятся) потребуется порядка 27,8 \% (5,8+22) от ежегодного общего выпуска системы профессионального образования, за исключением дополнительного профессионального образования. То есть только один из четырех закончивших обучение имеет шанс занять позицию, требующую высшего образования, при условии наличия вакансий естественного происхождения - выход на пенсию, увеличение числа рабочих мест.

Уровень подготовки специалистов среднего звена будет востребован для следующих трех позиций таблицы и составит 26,5 \% $(11,4+2,8+12,3)$ от ежегодного общего выпуска.

Уровень подготовки квалифицированных рабочих и служащих будет необходим для служащих (3,1 \%), работников сферы обслуживания (16\%), операторов $(15,5 \%)$ и в определенной степени для неквалифицированных рабочих $(11,1 \%)$. В сумме это составляет 45,7 \% от общего состава занятого населения.

Таким образом, предполагаемые вакансии для выпускников региональной системы профессионального образования распределены по уровню образования в следующей пропорции: высшее - 27,8 \%; среднее профессиональное (специалисты среднего звена) - 26,5 \%; среднее профессиональное (квалифицированные рабочие и служащие) $-45,7 \%$. 
Рассмотрим, каков ответ системы профессионального образования на необходимость воспроизводства существующей социально-профессиональной структуры. Высшее образование включает половину контингента получающих профессиональное образование. Остальная половина проходит подготовку в образовательных организациях среднего профессионального образования (табл. 2).

Таблица 2

Соотношение числа обучающихся в системе ПО

с кадровыми потребностями рынка труда, 2017 г.

\begin{tabular}{|l|c|c|c|}
\hline \multicolumn{1}{|c|}{ Уровень ПО } & $\begin{array}{c}\text { Потребность рынка } \\
\text { труда в выпускниках } \\
\text { системы ПО, \% }\end{array}$ & $\begin{array}{c}\text { Количество } \\
\text { выпускников на } \\
1000 \text { рабочей } \\
\text { силы }^{*}\end{array}$ & $\begin{array}{c}\text { Доля от общего } \\
\text { числа учащихся, } \\
\%^{*}\end{array}$ \\
\hline ВО & 27,8 & 135 & 49,5 \\
\hline СПО (специалисты ср. звена) & 26,5 & 49 & 38,2 \\
\hline СПО (кв. рабочие) & 45,7 & 100 & 12,3 \\
\hline
\end{tabular}

* Рассчитано по: [Статистический ежегодник 2018: 146-147].

Как видно, относительно равномерное распределение спроса и предложения труда приходится на уровень подготовки специалистов среднего звена, тогда как потребность в квалифицированных рабочих и служащих будет удовлетворена лишь на четверть. Совокупный запрос на выпускников среднего профессионального образования составляет $72,2 \%(26,5+45,7)$ от общего числа выпускников. Однако на практике он может быть удовлетворен лишь на 50,5 \% $(38,2+12,3)$.

Наиболее напряженно ситуация складывается с выпускниками высших учебных заведений. Получается, что доля студентов вузов превышает практически в 2 раза реально необходимое для воспроизводства существующей структуры количество. Данное явление, обозначенное Ф. Э. Шереги профессиональным и экономическим балластом, является избыточной квалификацией.

Другими словами, на рынке труда региона складывается обратная, в сравнении с образовательной сферой, тенденция. Так, по данным Республиканского агентства занятости населения, основная часть вакантных мест (59,4 \%) предназначена для специалистов с разным уровнем среднего профессионального образования. Более того, почти для четверти вакансий вообе не требуется специальное образование. На специалистов высшей квалификации приходится всего 16,8 \% вакансий [I] (рис.).

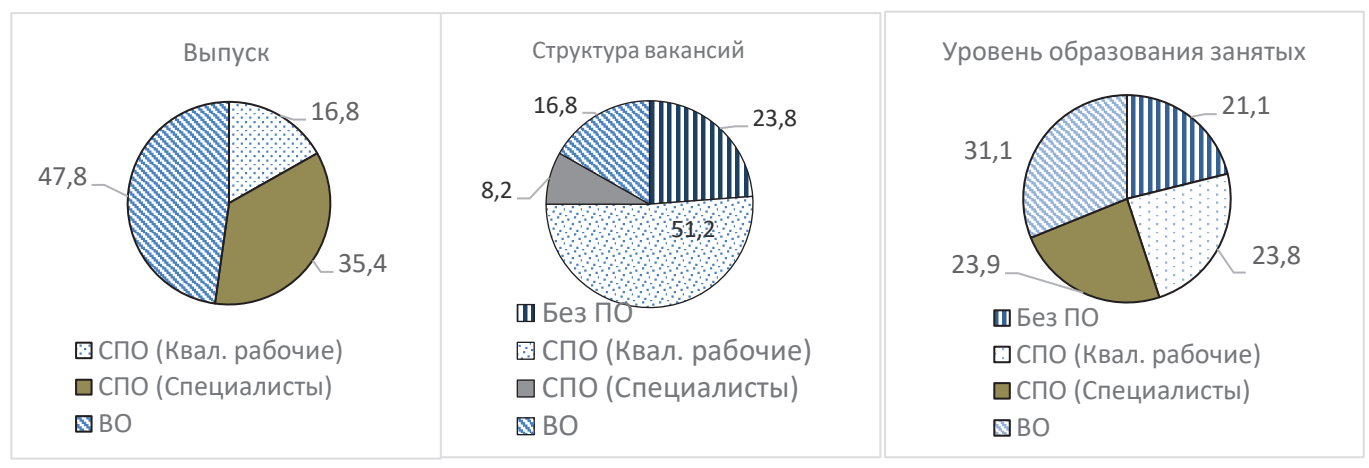

Рис. Структура выпуска кадров, вакансий и занятых по уровню образования, 2017 г., \% [Статистический ежегодник 2018: 169-170] 
Наиболее востребованными являются квалифицированные рабочие и служащие. Однако среди выпускников они составляют всего 16,8 \%. Зато имеет место избыток специалистов высшего уровня подготовки. Среди них преобладают экономисты и управленцы - 29,1 \%, а также юристы $-8,9$ \%. Доля каждой из остальных специальностей в общем числе выпускников не превышает 6,5 \%. На начальных этапах реформ структура подготовки кадров была более сбалансированной. В 1995 г. выпуск по специальности «экономика и управление» составлял 12,3%. Доминирование экономических специальностей в структуре выпуска началось с 2001 г. [Статистический ежегодник 2012: 132]

Сегодня, несмотря на снижение обозначенной тенденции, абитуриенты сохраняют высокую ориентацию на приобретение «избыточных» в экономике республики профессий экономического, социального и гуманитарного профилей. Особенно это касается абитуриентов, предполагающих обучение на платной основе. Чаще всего они выбирают экономику, муниципальное управление и рекламу, при этом мало уделяют внимания дефицитным инженерно-техническим специальностям. Значительное влияние на профессиональные предпочтения молодежи, помимо прочего, имеют примеры успешности карьеры и соответствующий социальный потенциал рабочего места. Среди этих характеристик ведущее место занимает размер заработной платы. На данный момент одна из самых высоких зарплат имеет место в финансовом секторе (54558,4 руб.) [Статистический ежегодник 2018]. Ее уровень в 3,6 выше, чем в самой низкооплачиваемой (операции с недвижимым имуществом). Поэтому для снижения перепроизводства необходимо выравнивание разрыва в межотраслевой и межпрофессиональной оплате труда.

Выявленная структура обучающихся на различных уровнях профессионального образования не соотносится с существующим распределением занятых, сложившимся на рынке труда. Получается, что запросы молодых людей существенно превышают возможности регионального рынка труда. Иначе говоря, уровень притязаний в основном не соответствует реальной социально-профессиональной структуре вакансий. Это ведет к росту безработицы и социальной напряженности в молодежной среде. Так, по данным российских исследователей, трое из четырех выпускников вузов не работают по полученной специальности или не могут устроиться по причине отсутствия вакансий [Грани российского образования 2015: 365]. В республике ориентировочно каждый третий безработный - это молодой человек в возрасте от 16 до 29 лет, а каждый восьмой безработный молодой человек - выпускник [II]. В сущности, данное явление - результат неэффективно потраченных, с экономической точки зрения, усилий, времени и средств. Для системы профессионального образования это явная дисфункция, которая имеет не только негативный экономический эффект, но может приводить к постепенной люмпенизации выпускников, профессиональные ожидания которых не оправдались. Происходит обесценивание вузовских дипломов и высшего образования, что ведет к снижению качества человеческого капитала в целом. Многие из получивших высокий уровень подготовки будут вынуждены занимать рабочие места, не требующие такой квалификации. По данным обследования населения по проблемам занятости, проведенного НИУ ВШЭ, каждый четвертый выпускник вуза выполняет работу, не требующую высшего образования [Варшавская 2017]. Названные тенденции имеют выраженный стагнирующий характер для экономики, а в социальной сфере порождают опасные напряжения и рост межпоколенческой конфликтности [Тюрина, Ключарев 2015: 290].

Рассмотренные количественные данные диктуют необходимость изменения структуры профессиональной подготовки и развития системы дополнительного профессионального образования как институционального регулятора рынка труда 
и воспроизводимой социальной структуры общества, которое позволяет в сжатые сроки «доводить» специалистов до требуемого уровня квалификации (компетенции). Таким образом, ДПО позволяет скорректировать недочеты, допущенные предыдущими уровнями профессионального образования, и обладает высоким модернизационным потенциалом в силу доступности для всех возрастных и профессиональных групп общества. Кроме того, в соответствии с принципом непрерывности образования, дополнительное профессиональное образование становится основным инструментом, с помощью которого выравниваются шансы учащихся, повышаются доступность и качество профессионального образования.

\section{Примечания}

I. Вакансии [Электронный ресурс]. - Режим доступа: http://burzan.govrb.ru/vakansii (дата обращения: 15.03.2018).

II. Данные отдела комплексного анализа, мониторинга рынка труда Республиканского агентства занятости населения.

\section{Источники и литература}

Статистический ежегодник: стат. сб. / Бурятстат. - Улан-Удэ, 2018. - 482 с.

Статистический ежегодник: стат. сб. / Госкомстат. - М., 2002. - 349 с.

Варшавская Е. Я. Где и кем работают высокообразованные россияне / Е. Я. Варшавская // Демоскоп Weekly. - 2017. - № 713-714. $644 \mathrm{c}$.

Грани российского образования. - М.: Центр социологических исследований, 2015. -

Тюрина И. О. Об индексе Шереги и возможностях количественного анализа социально-экономических процессов / И. О. Тюрина, Г. А. Ключарев // Россия реформирующаяся. Вып. 13: Ежегодник. - М.: Новый хронограф, 2015. - С. 287-302.

Шереги Ф. Э. Факторы противодействия модернизации российского профессионального образования / Ф. Э. Шереги // Модернизация российского образования: проблемы и перспективы. - М.: ЦСП, 2010. - С. 212-217.

Шереги Ф. Э. Образование как социальный институт: Функции и дисфункции / Ф. Э. Шереги // Россия реформирующаяся. Вып. 13: Ежегодник. - М.: Новый хронограф, 2015. C. $12-37$.

\section{References}

Statisticheskij ezhegodnik: stat. sb. / Buryatstat. - Ulan-Ude, 2018. - 482 s.

Statisticheskij ezhegodnik: stat. sb. / Goskomstat. - M., 2002. - 349 s.

Varshavskaya E. Ya. Gde i kem rabotayut vysokoobrazovannye rossiyane / E. Ya. Varshavskaya // Demoskop Weekly. - 2017. - № 713-714.

Grani rossijskogo obrazovaniya. - M.: Centr sociologicheskih issledovanij, 2015. - 644 s.

Tyurina I. O. Ob indekse Sheregi i vozmozhnostyah kolichestvennogo analiza social'noekonomicheskih processov / I. O. Tyurina, G. A. Klyucharev // Rossiya reformiruyushchayasya. Vyp. 13: Ezhegodnik. - M.: Novyj hronograf, 2015. - S. 287-302.

Sheregi F. E. Faktory protivodejstviya modernizacii rossijskogo professional'nogo obrazovaniya / F. E. Sheregi // Modernizaciya rossijskogo obrazovaniya: problemy i perspektivy. - M.: CSP, 2010. - S. 212-217.

Sheregi F. E. Obrazovanie kak social'nyj institut: Funkcii i disfunkcii / F. E. Sheregi // Rossiya reformiruyushchayasya. Vyp. 13: Ezhegodnik. - M.: Novyj hronograf, 2015. - S. 12-37. 